\title{
Managing Postoperative Astigmatism in Cataract Surgery: A Short Review
}

\section{Mohammed Abdulkarem* and Mustafa Ali Shata}

Department of Ophthalmology, Jeddah Eye Hospital, Saudi Arabia

*Corresponding Author: Mohammed Abdulkarem, Department of

Ophthalmology, Jeddah Eye Hospital, Saudi Arabia.

DOI: 10.31080/ASOP.2020.03.0148
Received: July 20, 2020

Published: July 25, 2020

(C) All rights are reserved by Mohammed

Abdulkarem and Mustafa Ali Shata.

\begin{abstract}
Cataract surgery is no more a visual rehabilitation surgery. Today along with cataract removal, astigmatism correction has become a routine procedure. Patients want a spectacle free life at any stage of life. 10 years before it was still impressive to have a residual of +2.0 D astigmatism following cataract surgery. But in last 10 years, a lot of technological advancement has happened. The residual astigmatism following cataract surgery has come down from $1.5 \mathrm{D}$ to $0.75 \mathrm{D}$, even $0.5 \mathrm{D}$ when a premium IOL is implanted. Here we are going to discuss in short the journey of astigmatism correction from choosing the incision in steep axis to Toric IOL implantation and so on.
\end{abstract}

Keywords: Astigmatism; Surgery; Limbal relaxing incisions (LRI)

\section{Introduction}

Cataract surgery has evolved a long way from being simple lens extraction to refractive procedure. Now a days patients wants a spectacle free life following cataract surgery. As a result it is utmost important to correct the pre-existing corneal astigmatism and also to reduce surgery induced astigmatism. Studies have shown that $35 \%-40 \%$ of cataract patients have $\geq 1.0 \mathrm{D}$ of astigmatism. And around $20 \%$ have $\geq 1.5$ D. A no of techniques along with special intra ocular lenses (IOLs) have been developed till now and the process is still evolving [1-3].

\section{Basic corneal architecture}

Incisions made during SICS or phacoemulcification surgery dissect the corneal lamellae and reduce tension between fibers. Change in tension, causes deformation of the shape of cornea and its resultant astigmatism. It is the size, shape, position and architecture of the incision which can determine the final astigmatic effect on it. Experiments by Koch, Kuglen has shown that induced astigmatism is proportional to the cube of the incision length [4].
Again the closer the incision is from visual axis, the more it causes astigmatism. As the cornea is more of oval in shape, so any incision in superior cornea is nearer to visual axis than temporal cornea. So superior incisions tends to produce more astigmatism than temporal incisions [8].

Cornea shows coupling effect due to distribution of corneal lamellae, which is steepening of axis, 90 degree away from flattened axis [5]. It is possible to plan the surgical incision in correct plane and reduce the pre existing astigmatism successfully. Limbal relaxing incisions (LRI), Clear corneal incisions (CCI), paired opposite clear corneal incision (OCCI), Toric IOL and bioptics are various approaches to advocate pre existing astigmatism.

\section{Pre OP evaluation}

Keratometry is quiet accurate to measure the steep axis for most of the patients. In cases of forme fruste keratoconus, arrested keratoconus, irregular astigmatism, post LASIK patients corneal topography can precisely tell the astigmatic nature of cornea. Surgically induced astigmatism (SIA) must be calculated specially in cases of 
low pre existing astigmatism or where premium IOL s are going to be implanted. It can be calculated from online calculators accurately. Post - op residual astigmatism should be less than $0.5 \mathrm{D}$ for patients seeking spectacle independence.

\section{Incision on steep meridian}

An easy way to reduce pre existing astigmatism is to place the incision on the steep meridian and flatten it. It works best for with the rule astigmatism. A clear corneal phaco incision of $3-3.2 \mathrm{~mm}$ induces 0.5 - $0.67 \mathrm{D}$ of astigmatism [6,7]. $2.4 \mathrm{~mm}$ induces 0.35 $0.21 \mathrm{D}$ of astigmatism. Whereas micro incisional phaco incisions less than $2.2 \mathrm{~mm}$ produces minimal flattening of cornea $[7,9]$.

Surgeon can predict up to $0.75 \mathrm{D}$ of SIA, and it best works when patient have less than $1 \mathrm{D}$ of pre existing astigmatism. Less than $0.5 \mathrm{D}$ astigmatism does not need correction. Up to $0.5 \mathrm{D}$ of myopic against the rule astigmatism apparently improves the near vision [10].

Astigmatism is higher in manual SICS surgery due to larger size. Moreover, temporal and supero temporal incision creates lesser astigmatism compared to superior incision. Approximately 1.28D of astigmatism is seen following SICS which can be recommended for patients having pre existing astigmatism more than $1 \mathrm{D}[11]$.

\section{Limbal relaxing incisions}

LRIs can correct (0.5 - 3.0) D of astigmatism [12]. A clear corneal incision, between 5 - $7 \mathrm{~mm}$ of optical zone, up to (90 - 95)\% depth of corneal thickness/600 micron, straight or arcuate incision, is given in the steep axis. Based on the age, amount of astigmatism, thickness of cornea the length of incision can be extended from 30 degree to 45,60 or even up to 90 degrees. As the incision is given in the mid periphery approximately $0.5 \mathrm{~mm}$ anterior to anterior limbal border, the chances of perforation, visual disturbances, dry eye are very less. Because of coupling action it flattens the steep axis along with steepen the axis 90 degree away from the original incision [16]. When the incision site fall on the arch area, one must be careful to first carry away with the surgery with the phaco surgery wound corresponding to the arc site, following extending the incision for astigmatic correction. Otherwise, chances of wound leak during surgery with anterior chamber instability can complicate the whole surgery.

Several nomograms are in use now a days to calculate the degree of arc like Donnenfield nomogram, Nichamin nomogram even online calculators are available at http://www.Iricalculator.com/ [13-15].

Proper centration is important as the effect of correction wins off with wrong axis selection for every 5 degree. Cyclorotation of eye should be kept in mind and eye should be marked in proper axis before starting surgery. Verion and Callisto are wonderful devices to mark the correctly. Now a days femtosecond laser is used for LRIs, its available on Intralase (Abbott Medical Optics) on LenSx, LensAR, Victus, OptiMedica $[17,18]$.

Eyes with corneal ectasia, irregular astigmatism are not advised for LRIs. LRI s are better suited for regular astigmatism but many studies state that, their predictability is questionable [19].

\section{Paired opposite clear corneal incisions (POCCI)}

This technique was first described by Lever and Dahan of placing another clear corneal incision 180 degree opposite to the first CCI [20]. It enhances the effect of first incision and do not need any special instruments to make it. According to Lever and Dehen POCCI corrects astigmatism up to $1.5 \mathrm{D}$. But the technique is not much popular due to lack of predictability, absence of nomogram and higher risk of post op infection due to multiple incisions [21].

\section{Toric IOL implantation}

Toric IOL was first invented in 1988. It is much more predictable than the other techniques used before. From 0.75 - upto $6.0 \mathrm{D}$ of astigmatism can be corrected with toric IOLs [22,23].

It can correct astigmatism at any axis. But if the lens rotates following surgery it reduces the astigmatic power of the lens. Rotation of 10 degree reduces astigmatic correction by one third, 20 degree by two third and by $>30$ degree rotation the astigmatic correction becomes nil $[24,25]$. It is very important to place the axis of the lens correctly and remove and visco elastic substance behind IOL to prevent post op rotation. In myopic eyes or eyes with pseudoexfoliation, placing a CTR to prevent rotation is advisable. Alcon AcrySof Toric lenses T6 - T9 corrects up to 6D in the IOL plane where 4.0 D is corrected in corneal plane. These lenses are coated with adhesive material which maintains their stability furthermore [26].

The IOL power can be calculated from Toric IOL calculator online at http://www.acrysoftoriccalculator.com. 
Now monofocal and presbyopia correcting extended depth toric IOLs also have come to market. AMO TECHNIS Toric from $\mathrm{Ab}$ bott medical optics has toric IOLs which corrects from 1.00D - 4.0D of astigmatism and they have lenses of +5D to +34D [26]. Regular astigmatism is best treated with toric, even in cases of arrested keratoconus, pseudoexfoliation patients it has shown good results, but long term multicentric study is still lacking.

\section{Future of astigmatism correction}

Intra operative aberrometry uses wavefront technology and real-time information during surgery. It takes accountability of aphakic astigmatism, SIA, posterior corneal astigmatism while calculating the IOL power. Eyelid speculum pressure, corneal hydration, viscoelastic substances - they poses drawback in the process but few multicentric studies are going on in this era to find out the possible correction. Almost a perfect IOL power can be placed in bag by this method but its still in an early stage of development. Despite all the measures, residual astigmatism is still seen. Ideally it should be $<0.75 \mathrm{D}$. Resultant refractive error following cataract surgery can be corrected by laser refractive procedures like LASIK or for older patients with PRK. In extreme conditions even Piggyback IOLs can be tried too. Barrett's toric calculator, Abulafia-Koch formula are pretty good in calculating IOL powers now [27].

\section{Conclusion}

Cataract surgery has come a long way and its evolving more towards robotics now. As a cataract surgeon it has become a responsibility to give our patients, as minimal residual astigmatism as possible. With evolving technology, spectacle free life is not very difficult to achieve for everyone anymore.

\section{Financial Interest Disclosure}

The authors of the article have no financial interest of any instrument/procedure aforementioned.

\section{Bibliography}

1. Ferrer-Blasco T., et al. "Prevalence of corneal astigmatism before cataract surgery". Journal of Cataract and Refractive Surgery 35.1 (2009): 70-75.

2. Michelitsch M., et al. "Prevalence of agr-related changes of corneal astigmatism in patients before cataract surgery". Ophthalmologe 114.3 (2017): 247-251.
3. Khan MI and Muhtaseb M. "Prevalence of corneal astigmatism in patients having routine cataract surgery at a teaching hospital in the United Kingdom". Journal of Cataract and Refractive Surgery 37.10 (2011)1:1751-1755.

4. Armeniades CD., et al. "Effect of incision length, location, and shape on local corneoscleral deformation during cataract surgery". Journal of Cataract and Refractive Surgery 16.1 (1990): 83-87.

5. Gills JP and Rowsey JJ. "Managing coupling in secondary astigmatic keratotomy". International Ophthalmology Clinics 43.3 (2003): 29-41.

6. Amesbury EC and Miller KM. "Correction of astigmatism at the time of cataract surgery". Current Opinion in Ophthalmology 20.1 (2009): 19-24.

7. Masket S., et al. "Induced astigmatism with 2.2 and $3.0 \mathrm{~mm}$ coaxial phacoemulcification incisions". Journal of Refractive Surgery 25.1 (2009): 21-24.

8. Hashemi H., et al. "The location of incision in cataract surgery and its impact on induced astigmatism". Current Opinion in Ophthalmology 27.1 (2016): 58-64.

9. Alpins N., et al. "Asymmetric corneal flattening effect after small incision cataract surgery". Journal of Refractive Surgery 32.9 (2016): 598-603.

10. F Ttindade., et al. "Benefit of against -the-rule astigmatism to uncorrected near acuity". Journal of Cataract and Refractive Surgery 23 (1997): 83-85.

11. Gokhale NS and Sawhney S. "Reduction in astigmatism in mannual small incision cataract surgery through change of incision site". Indian Journal of Ophthalmology 53 (2005): 201-203.

12. Nichamin LD. "Management of astigmatism in conjunction with lens surgery". In: Tasman WM, ed. Duane's Ophthalmology. Philadelphia: Lippincott Wilkins (2006).

13. Gills JP. Nomogram for Limbal Relaxing Incisions with cataract surgery. Tapron Springs, FL: St. Luke's Cataract and Laser Institute 199.

14. Wang L., et al. "Peripheral corneal relaxing incisions combined with cataract surgery". Journal of Cataract and Refractive Surgery 29 (2003): 712-722. 
15. Cristobal JA., et al. "Effect of limbal relaxing incisions during phacoemulcification surgery based on nomogram review and numerical simulation". Cornea 28.9 (2009): 1042-1049.

16. Carvalho MJ., et al. "Limbal relaxing incisions to correct corneal astigmatism during phacoemulcification". Journal of Refractive Surgery 23.5 (2007): 499-504.

17. Mozayan E and Lee JK. "Update on astigmatism management". Current Opinion in Ophthalmology 25.4 (2014): 286-290.

18. Ruckl T., et al. "Femtosecond laser - assisted intrastromal arcuate keratotomy to reduce corneal astigmatism". Journal of Cataract and Refractive Surgery 39.4 (2013): 528-538.

19. Hirnschall N., et al. "Correction of moderate corneal astigmatism during cataract surgery: toric intraocular lens versus peripheral corneal relaxing incisions". Journal of Cataract and Refractive Surgery 201440 (3): 354-361.

20. Lever J and Dahan E. "Opposite clear corneal incisions to correct pre-existing astigmatism in cataract surgery". Journal of Cataract And Refractive Surgery 26 (2000): 803-805.

21. Bazzazi N., et al. "Opposite clear corneal incisions versus steep Meridian incision phacoemulcification for correction of preexisting astigmatism". Journal of Ophthalmic and Vision Research 3.2 (2008): 87-90.

22. Alfonso JF., et al. "Clinical outcomes after bilateral implantation of an apodized +3.0 D toric diffractive multifocal lens". Journal of Cataract and Refractive Surgery 40.1 (2014): 51059.

23. Agresta B., et al. "Visual acuity improvement after implantation of toric IOL lenses in cataract patients with astigmatism: a systemic review". BMC Ophthalmology 12 (2012): 41.

24. Leyland M., et al. "Prospective evaluation of a plate heptic toric intraocular lens". Eye 15.2 (2001): 202-205.

25. Sun XY., et al. "Toric intraocular lenses for correcting astigmatism in 130 eyes". Ophthalmology 107.9 (2000): 1776-1781.

26. Maria X., et al. "Consensus on the management of astigmatism in cataract surgery". Clinical Ophthalmology 13 (2019): 311324.

27. Mukesh T. "Management of astigmatism in cataract". DJO 7 (2015).

\section{Assets from publication with us}

- Prompt Acknowledgement after receiving the article

- Thorough Double blinded peer review

- Rapid Publication

- Issue of Publication Certificate

- High visibility of your Published work

Website: www.actascientific.com/

Submit Article: www.actascientific.com/submission.php

Email us: editor@actascientific.com

Contact us: +919182824667 